\title{
Hydroxyethyl starch vs Haemaccel in subarachnoid block - Let's kill the tension of hypotension
}

\author{
Kawin Kumar M
}

Assistant Professor, Department of Anaesthesiology, Srimuthukumaran Medical College \& Hospital, Chennai, Tamil Nadu, INDIA. Email: kawinkumar8419@gmail.com

\begin{abstract}
Background: To compare the efficacy of Hydroxyethyl Starch $6 \%$ and Haemaccel in reducing the incidence and severity of hypotension after subarachnoid block (SAB). Design: A prospective randomized controlled double-blind study. Materials and methods: 100 patients in the age group of 25 to 60 years of ASA Grade I and II scheduled for elective lower abdominal and lower limb surgeries were randomly allocated into two groups. Group 1 received $10 \mathrm{ml} / \mathrm{kg}$ of Haemaccel and Group 2 received $10 \mathrm{ml} / \mathrm{kg}$ of HES $6 \%, 15$ minutes prior to spinal anaesthesia. Pulse rate, systolic, diastolic and mean arterial blood pressure was recorded at, every 2 minutes for the first 10 minutes, every 5 minutes for the next 50 minutes and every 10 minutes till the end of surgery after subarachnoid block. Results: The incidence of hypotension was $9 \%$ in Group 1 and 4\% in Group 2, which was statistically significant. The ephedrine bolus requirements were less in Group 2 (4 of 50 patients) when compared to Group 1 (11 of 50 patients). Interpretation and Conclusion: It was observed from our study that HES (6\%) reduces incidence of hypotension after subarachnoid block and also required lesser mean dose requirements of ephedrine when compared to Haemaccel. In conclusion we found that colloids reduces incidence of spinal anaesthesia induced hypotension and 6\% HES is safer, effective than Haemaccel in preventing hypotension and achieving haemodynamic goals in patients undergoing surgeries under SAB. Thus among colloids, HES $6 \%$ appears to be a promising plasma volume expander.
\end{abstract}

Key words: Hypotension; Preloading; Colloids; 6\% Hydroxyethyl Starch (HES); Haemaccel, Subarachnoid block (SAB).

\section{*Address for Correspondence:}

Dr Kawin Kumar, 3B/10 Gokulam Phase 2 Apartment, Sriram Nagar Main Road, Near Nolambur Busstand, Mogappair West, Chennai 600095 Email: kawinkumar8419@gmail.com

Received Date: 13/05/2020 Revised Date: 02/06/2020 Accepted Date:27/06/2020

DOI: https://doi.org/10.26611/10151523

This work is licensed under a Creative Commons Attribution-NonCommercial 4.0 International License. (cc)) EY-NC

\begin{tabular}{|l|l|}
\hline \multicolumn{2}{|c|}{ Access this article online } \\
\hline Quick Response Code: & Website: \\
\hline & www.medpulse.in \\
& \\
\hline
\end{tabular}

\section{INTRODUCTION}

Hypotension, with an incidence of $15 \%$ to $33 \%$, is one of the most frequent side effects of spinal anaesthesia ${ }^{1}$. The administration of large volumes of IV fluids before spinal anaesthesia to prevent hypotension has become an increasingly common practice ${ }^{2,3}$. However, the efficacy of fluid administration before spinal block has been tested mostly in obstetric patients ${ }^{4-6}$, only few studies have evaluated the value of fluid administration before spinal block in general surgery patients ${ }^{7-11}$. Crystalloid administration prior to spinal anaesthesia has been practiced traditionally to reduce the incidence of hypotension, although its value is questionable ${ }^{4,5}$. Hypotension associated with spinal anaesthesia cannot be completely eliminated by crystalloid preloading as crystalloid solutions have a short intravascular half-life and are poor plasma volume expanders. Colloid solutions which remain in the circulation for a longer period seem to be an effective alternative. Some authors have observed improved haemodynamic effects during spinal anaesthesia after the administration of colloid solutions ${ }^{12,13}$. However, the ideal fluid regimens scheduled for spinal anaesthesia is controversial $^{14,15}$. Moreover, with increasingly available various colloid solutions, attention need to be given to the 
different properties of these colloids. This study was mainly intended to compare the efficacy of Hetastarch $(6 \%)$ to that of Haemaccel in preventing the incidence and severity of hypotension and maintaining haemodynamic status in patients undergoing surgeries under spinal anaesthesia.

\section{AIMS AND OBJECTIVES:}

The aim of our study was to unveil the fact that preloading with colloids decreases the incidence of spinal anaesthesia induced hypotension. The study also intended to compare the efficacy of HES 6\% and Haemaccel among colloids, in reducing the incidence and severity of hypotension after subarachnoid block.

SPINAL ANAESTHESIA:

Intimate knowledge of the anatomy of the vertebral column and its contents is the key stone to successful, safe spinal anaesthesia, not only in terms of the performance of lumbar puncture but also in terms of the spread of local anaesthetics in CSF and the level of anaesthesia achieved. In spinal anaesthesia, the anaesthetic agent is brought into contact with neural structures in the subarachnoid space. Most of the physiologic side effects of spinal anaesthesia are a consequence of the sympathetic blockade ${ }^{16}$. Preload is an important determinant of cardiac output. During spinal anaesthesia cardiac output remains unchanged in normovolemic patients as long as they are positioned with the legs elevated above the level of the heart. Heart rate characteristically decreases during spinal anaesthesia in the absence of autonomically active drugs. Myocardial oxygen demands decrease along with $10 \%$ decrease in hepatic blood flow.

Hydroxy Ethyl Starch-HES:

HES is made from wax cornstarch, more than $95 \%$, which consists of high molecular weight amylopectin. The extent and duration of volume expansion achieved by HES depend on their concentration, the degree of molar substitution and the substitution pattern. HES $6 \%$ contains approximately 5 hydroxyethyl groups per 10 glucose units, molar substitution of $0.5^{17-29}$. Following the infusion of HES there is initially a rapid amylase-dependent breakdown and renal excretion. Plasma half life is 5 days and $90 \%$ is eliminated in 42 days $^{20}$. The increase in colloid osmotic pressure obtained with HES is equivalent to albumin. HES results in 100\% volume expansion similar to $5 \%$ albumin. It results in greater volume expansion as compared to gelatins ${ }^{24}$. Duration of volume expansion is usually 8-12 hours ${ }^{22}$.

Advantages: Cost effectiveness and Maximum allowable volume.

Disadvantages:

The first and second-generation HES (Hextend, Hetastarch, Pentastarch) are associated with various sideeffects as follows:
1. Coagulation: HES administration is associated with reduction in circulating factor VIII and von Willebrand factor levels, impairment of platelet function, prolongation

2. of partial thromboplastin time and activated partial thromboplastin time and increases bleeding complications $^{22,}$, $5-27$.

3. 2.Accumulation: High molecular weight (HMW) HES are associated with greater degree of accumulation in interstitial spaces and reticuloendothelial system. It gets deposited in various tissues including skin, liver, muscle, spleen, intestine, trophoblast and placental stroma. Such depositions have been associated with pruritus ${ }^{22}$, 26, 28 . Anaphylactoid Reactions ${ }^{26}$.

4. Renal impairment: HMW HES has been found to be associated with increased creatinine levels, oliguria, acute renal failure in patients who were critically ill with existing renal impairment ${ }^{29,30}$. HMW HES is associated with development of osmotic nephrosis ${ }^{30,31}$.

5. Increase in serum amylase levels ${ }^{22,23}$.

Indications: Surgery (haemorrhagic shock), Injuries (traumatic shock), Infections (septic shock), Burns, Saving of donor blood during surgery. Example: Acute

normovolemic haemodilution.

Contraindications: Severe congestive cardiac failure., Renal failure (serum creatinine $>2 \mathrm{mg} / \mathrm{dl}$ ), Severe coagulation disturbances, Excess fluid overload (hyper hydration), Cerebral haemorrhage.

Haemaccel:

Gelatin is the name given to the proteins formed when the connective tissues of animals are boiled. They have the property of dissolving in hot water and forming a jelly when cooled. Gelatin is thus a large molecular weight protein formed from hydrolysis of collagen ${ }^{22,23,32}$. Polygeline ('Haemaccel', Hoechst) is produced by the action of alkali and then boiling water (thermal degradation) on collagen from cattle bones.

Indications: Hypovolemia due to acute blood loss, Acute normovolaemic haemodilution ${ }^{33}$, Extracorporeal circulation - cardiopulmonary bypass ${ }^{34}$, Volume preloading prior to regional anaesthesia.

Contraindications: Known hypersensitivity to constituents of the preparation, History of anaphylactoid reactions.

Advantages:

1. Cost effective: It is cheaper as compared to albumin and other synthetic colloids.

2. No limit of infusion: Gelatins do not have any upper limit of volume that can be infused as compared to both starches and dextrans.

3. No effect of renal impairment: Gelatins are readily 
excreted by glomerular filtration as they are small sized molecules. Gelatins are associated with lesser renal impairment as compared to HMW HES $^{26,32}$.

Disadvantages:

1. Anaphylactoid reactions: Gelatins are associated with higher incidence of anaphylactoid reactions as compared to natural colloid albumin ${ }^{26}$.

2. Effect on coagulation: The effect of gelatins on coagulation is not clear. There are studies which support activation of coagulation by gelatins ${ }^{65}$ and there are some studies which reveal increased bleeding time, impaired platelet adhesiveness during cardiac surgery ${ }^{35}$.

3. Circulatory disturbance: Gelatins are associated with occurrence of circulatory dysfunction marked by increased plasma renin activity and aldosterone in patients with ascites undergoing large-volume paracentesis ${ }^{36}$.

\section{METHODOLOGY:}

A randomized study was conducted on 100 patients undergoing elective operative procedures under spinal anaesthesia for lower abdominal and lower limb surgeries at Muthukumaran Medical College and Hospital.

Inclusion criteria:

1. Elective cases with ASA physical status 1 and 2.

2. Age between 25 and 60 years.

Exclusion criteria:

- Emergency surgeries.

- Severe anaemia, coagulation abnormalities and bleeding disorders.

- Patients with previous history of surgeries on the spine.

- Patients with spinal deformities.

- Patients with history of backache.

- Patients with active skin lesions over lumbosacral region.

- Patients with h/o hypersensitivity.

Preanaesthetic Examination and Preparation

The study protocol was approved by the Hospital Ethical committee and Ethical clearance was obtained from the institution for the study. Preanaesthetic check-up was done one day prior to the surgery. All the Patients were visited and detailed Preanaesthetic examination including history, clinical examination, systemic examination of cardiovascular, respiratory and central nervous system and examination of spine for deformity, infection was carried out. The procedure of subarachnoid block was explained to the patients and informed written consent was obtained. Basic laboratory investigations like complete haemogram, bleeding time, clotting time, blood sugar, blood urea, serum creatinine and urine analysis were carried out routinely on all patients. ECG was done in patients more than 40 years of age and chest $x$-ray when indicated.

Premedication:

To allay anxiety and apprehension, all patients were given Tablet Diazepam $0.2 \mathrm{mg} / \mathrm{kg}$ body weight the night before the surgery. Patients were kept nil orally from previous night of surgery.

\section{METHODOLOGY:}

100 ASA I and II patients posted for lower abdominal and lower limb surgeries under spinal anaesthesia were randomly allocated into

Group 1- received 10m1/kg Haemaccel.

Group 2- received $10 \mathrm{ml} / \mathrm{kg}$ of $6 \%$ HES.

Preparation of operating room:

Boyle's anaesthesia machine was checked. Appropriate size endotracheal tubes, working laryngoscope with medium and large size blades, stylet and working suction apparatus were kept ready before the procedure. Emergency drug were also kept available.

Procedure

Patients were moved to operation theatre where IV line was secured with $18 \mathrm{G}$ cannula. Baseline heart rate, systolic blood pressure and diastolic blood pressure were measured in supine position using a mercury sphygmomanometer. Mean arterial blood pressure was derived from the formula, $\mathrm{MAP}=\mathrm{DBP}+\mathrm{PP} / 3$. The fluids were administered prior to spinal anaesthesia over duration of 15 minutes. After intravascular fluid administration, pulse rate and blood pressure were measured. With all aseptic precautions, patient in lateral position, subarachnoid block was performed at L3-L4 interspace with a $25 \mathrm{G}$ spinal needle using $3.2 \mathrm{ml}$ of $0.5 \%$ bupivacaine heavy. The patient was turned to supine position immediately and the level of anaesthesia determined by pinprick method. Pulse rate, systolic, diastolic and mean arterial blood pressure was recorded at, every 2 minutes for the first 10 minutes, every 5 minutes for the next 50 minutes and every 10 minutes till the end of surgery after subarachnoid block. Hypotension was defined as decrease in systolic blood pressure to less than $90 \mathrm{~mm}$ of $\mathrm{Hg}$ or $70 \%$ of the baseline values whichever is greater. Hypotension was treated by an intravenous titrated doses of ephedrine repeated as necessary until the blood pressure was increased to $>70 \%$ of the baseline value. Bradycardia (heart rate less than $50 / \mathrm{min}$ ) when encountered was treated with $0.6 \mathrm{mg}$ of atropine. After preloading all patients were given ringer lactate at the rate of $1.5 \mathrm{ml} / \mathrm{kg} / \mathrm{hr}$ as maintenance fluid. The number of patients developing hypotension as well the mean dose of ephedrine required for treatment was noted.

STATISTICAL METHODS ${ }^{37-40}$

Descriptive statistical analysis has been carried out in the present study. Results on continuous measurements are 
presented on Mean SD (Min-Max) and results on categorical measurements are presented in Number (\%). Significance is assessed at 5\% level of significance. Student ' $t$ 'test( two tailed, independent) has been used to find the significance of study parameters on continuous scale between two groups (Inter group analysis)
* Moderately significant $(\mathrm{P}$ value: $<\mathrm{P}<0.05)$

$* *$ Strongly significant $(\mathrm{P}$ value $<0.01)$ Statistical software: the statistical software namely SAS 9.2, SPSS 15.0, Stata 13.0, Med-Calc 9.0.1 and Systat 12.0 were used for the analysis of the data and Microsoft word and Excel have been used to generate graphs, tables etc.

\section{OBSERVATIONS AND RESULTS}

Study design: A comparative study of two groups consisting of 50 patients each, is taken up for investigating prospectively the efficacy and efficiency of each group in preventing spinal induced hypotension.

Group 1: 50 patients who received, $10 \mathrm{ml} / \mathrm{kg}$ Haemaccel 15 minutes prior to spinal anaesthesia.

Group 2: 50 patients who received Hydroxyethyl starch $6 \%, 10 \mathrm{ml} / \mathrm{kg} 15$ minutes prior to spinal anaesthesia.

Table 1: The background characteristics of two groups

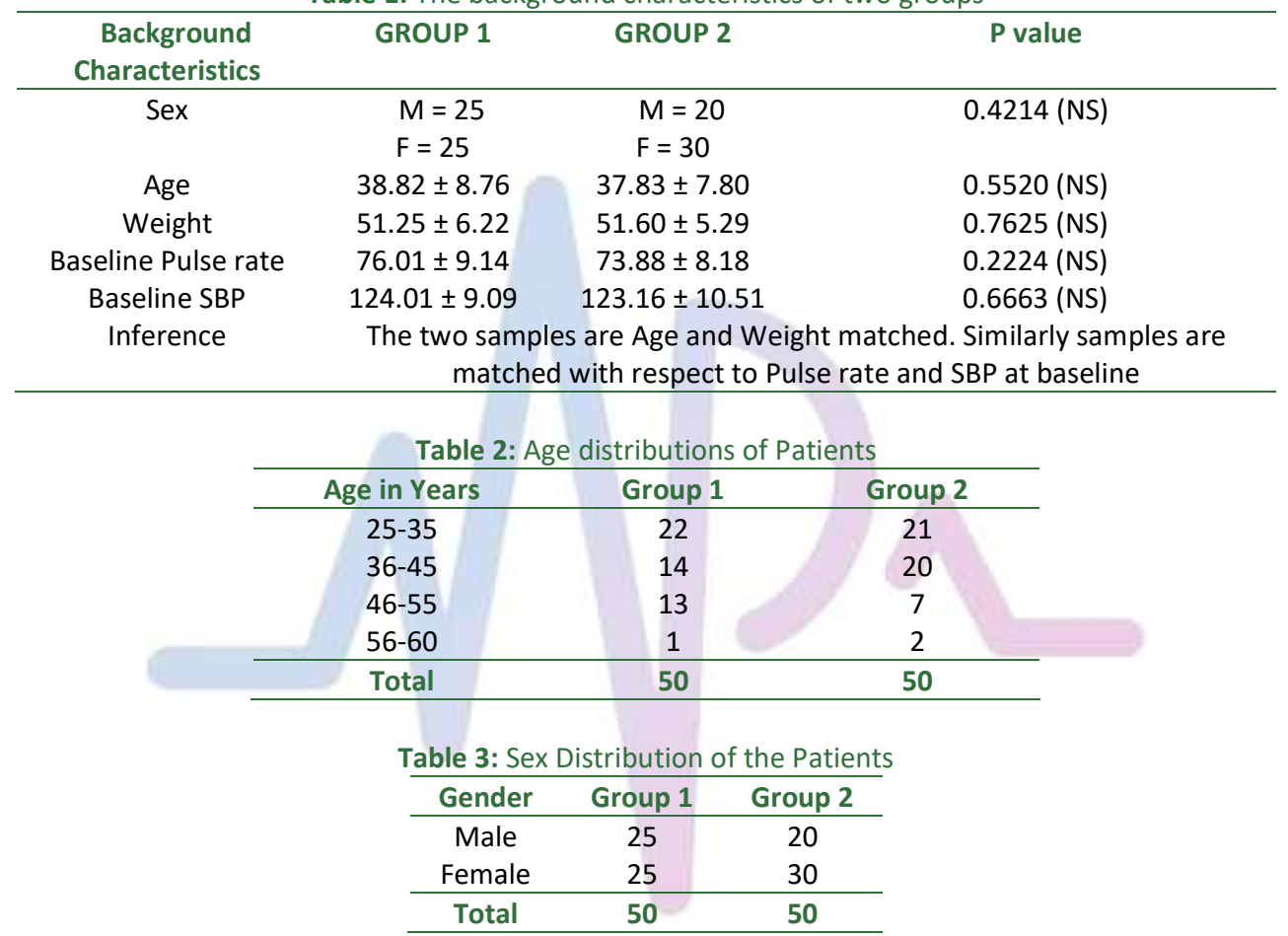

Table 1-3 shows the background characteristics of the two groups. The two groups were comparable in respect to age, weight, and sex. All the patients belonged to ASA grade 1 and 2. The baseline pulse rate and the systolic blood pressure were not significantly different Anaesthesia was adequate in all the patients and there was no need for supplementation. Level of block was between T8 and T10 in two groups. Blood loss was minimal in all the patients.

\begin{tabular}{ccc}
\multicolumn{3}{c}{ Table 4: Type of Surgery } \\
\hline & GROUP 1 & GROUP 2 \\
\hline Gynaecology & 23 & 25 \\
General Surgery & 27 & 25 \\
\hline Total & 50 & 50
\end{tabular}

Table 4 shows no significant difference in the type of surgeries in between the two groups.

\begin{tabular}{cccc} 
& \multicolumn{4}{c}{ Table 5: Duration of Surgery } & \\
\hline Time in Minutes & GROUP 1 & GROUP 2 & P Value \\
\hline $30-50$ & 7 & 9 & \\
$60-80$ & 34 & 32 & \\
$90-110$ & 5 & 5 & \\
$>120$ & 4 & 4 & $P=0.8952$ (NS) \\
Total & 50 & 50 & \\
\hline
\end{tabular}




\begin{tabular}{|c|c|c|c|}
\hline \multicolumn{4}{|c|}{ Duration of surgery is statistically comparable in both groups } \\
\hline \multicolumn{4}{|c|}{ Table 6: Comparison of Pulse rate } \\
\hline TIME & GROUP 1 Mean \pm SD & GROUP 2 Mean \pm SD & $P$ value \\
\hline Baseline & $73.88 \pm 8.18$ & $76.30 \pm 9.15$ & $P=0.1664(N S)$ \\
\hline After Preloading & $80.17 \pm 8.51$ & $82.59 \pm 10.61$ & $P=0.2113(N S)$ \\
\hline $1 \mathrm{~min}$ & $84.01 \pm 10.82$ & $87.22 \pm 12.22$ & $P=0.1675(N S)$ \\
\hline $2 \mathrm{~min}$ & $84.07 \pm 10.95$ & $85.49 \pm 13.24$ & $P=0.5603(N S)$ \\
\hline $4 \mathrm{~min}$ & $82.89 \pm 10.22$ & $85.80 \pm 13.63$ & $P=0.2302(N S)$ \\
\hline $6 \min$ & $80.83 \pm 9.78$ & $84.53 \pm 12.74$ & $P=0.1065(N S)$ \\
\hline $8 \mathrm{~min}$ & $80.09 \pm 9.48$ & $83.26 \pm 12.57$ & $P=0.1577(N S)$ \\
\hline $10 \mathrm{~min}$ & $79.14 \pm 9.36$ & $82.16 \pm 12.02$ & $P=0.1642(N S)$ \\
\hline $15 \mathrm{~min}$ & $76.96 \pm 8.94$ & $80.10 \pm 12.48$ & $P=0.1516(N S)$ \\
\hline $20 \mathrm{~min}$ & $74.99 \pm 8.37$ & $78.80 \pm 11.77$ & $\mathrm{P}=0.0090\left(^{* *}\right)$ \\
\hline $25 \mathrm{~min}$ & $73.65 \pm 7.87$ & $77.31 \pm 11.80$ & $P=0.0106(*)$ \\
\hline $30 \mathrm{~min}$ & $73.93 \pm 7.26$ & $74.76 \pm 9.95$ & $P=0.6349(N S)$ \\
\hline $35 \mathrm{~min}$ & $72.51 \pm 7.58$ & $73.35 \pm 9.03$ & $P=0.6155(N S)$ \\
\hline $40 \mathrm{~min}$ & $71.13 \pm 7.56$ & $72.27 \pm 8.44$ & $P=0.4785$ (NS) \\
\hline $45 \mathrm{~min}$ & $70.69 \pm 7.02$ & $70.69 \pm 8.17$ & $P=1.0000(N S)$ \\
\hline $50 \mathrm{~min}$ & $70.48 \pm 6.99$ & $71.51 \pm 7.88$ & $P=0.4909(N S)$ \\
\hline $55 \mathrm{~min}$ & $69.37 \pm 7.54$ & $70.78 \pm 7.68$ & $P=0.3565(N S)$ \\
\hline $60 \mathrm{~min}$ & $70.54 \pm 5.79$ & $71.51 \pm 6.93$ & $P=0.4494(N S)$ \\
\hline $70 \mathrm{~min}$ & $69.47 \pm 8.79$ & $67.84 \pm 9.90$ & $P=0.3861(N S)$ \\
\hline $80 \mathrm{~min}$ & $73.09 \pm 10.12$ & $68.50 \pm 8.39$ & $P=0.1858(N S)$ \\
\hline $90 \mathrm{~min}$ & $75.83 \pm 9.11$ & $70.28 \pm 7.65$ & $P=0.1552(N S)$ \\
\hline $100 \mathrm{~min}$ & $70.82 \pm 7.73$ & $70.62 \pm 7.85$ & $P=0.8981(N S)$ \\
\hline $110 \mathrm{~min}$ & $73.00 \pm 4.24$ & $70.64 \pm 7.54$ & $P=0.6818(N S)$ \\
\hline $120 \mathrm{~min}$ & $70.80 \pm 5.66$ & $70.00 \pm 7.46$ & $P=0.5472(N S)$ \\
\hline
\end{tabular}

*Statistical Significance at 5\%: ** Statistical Significance at $1 \%$ : NS Not Significant.

Table 6 shows the change in mean pulse rate during the study. It can be observed that the baseline pulse rate values for all the three groups are similar and are statistically insignificant. It can also be seen that there is a slight increase in the pulse rate values in both the groups after preloading and in the first fifteen to twenty five minutes after spinal anaesthesia. However, there is no statistically significant change in pulse rate values among the two groups upto fifteen minutes. At twenty and twenty five minutes a fall in pulse rate in Group 1 was greater than Group 2 and it was statistically significant.

\begin{tabular}{|c|c|c|c|}
\hline TIME & GROUP 1 Mean \pm SD & GROUP 2 Mean \pm SD & P value \\
\hline Baseline & $122.23 \pm 9.01$ & $121.76 \pm 10.51$ & $P=0.8108$ (NS) \\
\hline After Preloading & $126.60 \pm 7.78$ & $127.18 \pm 8.69$ & $P=0.7259$ (NS) \\
\hline $1 \mathrm{~min}$ & $127.30 \pm 7.11$ & $126.09 \pm 8.89$ & $P=0.4541$ (NS) \\
\hline $2 \min$ & $121.49 \pm 7.34$ & $122.22 \pm 8.67$ & $P=0.6505(N S)$ \\
\hline $4 \mathrm{~min}$ & $117.28 \pm 7.01$ & $118.77 \pm 7.60$ & $P=0.3107(N S)$ \\
\hline $6 \mathrm{~min}$ & $114.22 \pm 6.58$ & $115.12 \pm 7.02$ & $P=0.5099$ (NS) \\
\hline $8 \mathrm{~min}$ & $112.77 \pm 6.08$ & $113.24 \pm 6.48$ & $P=0.7092$ (NS) \\
\hline $10 \mathrm{~min}$ & $108.69 \pm 7.11$ & $111.66 \pm 7.17$ & $\mathrm{P}=0.0037(* *)$ \\
\hline $15 \mathrm{~min}$ & $101.15 \pm 7.71$ & $107.87 \pm 6.01$ & $\mathrm{P}=0.0001\left(^{* *}\right)$ \\
\hline $20 \mathrm{~min}$ & $102.88 \pm 7.07$ & $107.35 \pm 6.66$ & $\mathrm{P}=0.0001(* *)$ \\
\hline $25 \mathrm{~min}$ & $106.53 \pm 6.80$ & $108.49 \pm 5.14$ & $P=0.0225\left(^{*}\right)$ \\
\hline $30 \mathrm{~min}$ & $107.93 \pm 5.48$ & $108.62 \pm 5.28$ & $P=0.5229(N S)$ \\
\hline $35 \mathrm{~min}$ & $109.63 \pm 5.40$ & $111.06 \pm 4.65$ & $P=0.1591$ (NS) \\
\hline $40 \mathrm{~min}$ & $111.26 \pm 4.75$ & $112.02 \pm 4.02$ & $P=0.3899$ (NS) \\
\hline $45 \mathrm{~min}$ & $112.34 \pm 4.89$ & $113.48 \pm 4.94$ & $P=0.2490(N S)$ \\
\hline $50 \mathrm{~min}$ & $111.81 \pm 4.75$ & $112.99 \pm 5.18$ & $P=0.2380(N S)$ \\
\hline $55 \mathrm{~min}$ & $112.50 \pm 4.77$ & $113.39 \pm 5.79$ & $P=0.4036$ (NS) \\
\hline $60 \mathrm{~min}$ & $113.50 \pm 4.38$ & $113.73 \pm 4.77$ & $P=0.8022(N S)$ \\
\hline $70 \mathrm{~min}$ & $114.85 \pm 3.96$ & $113.61 \pm 9.04$ & $P=0.3775$ (NS) \\
\hline $80 \mathrm{~min}$ & $115.21 \pm 4.86$ & $113.82 \pm 7.05$ & $P=0.2542$ (NS) \\
\hline $90 \mathrm{~min}$ & $114.89 \pm 4.61$ & $113.50 \pm 4.51$ & $P=0.1307(N S)$ \\
\hline $100 \mathrm{~min}$ & $113.23 \pm 4.30$ & $114.80 \pm 4.20$ & $P=0.0678(N S)$ \\
\hline $110 \mathrm{~min}$ & $116.00 \pm 4.65$ & $114.50 \pm 9.19$ & $P=0.3065(N S)$ \\
\hline $120 \mathrm{~min}$ & $113.25 \pm 3.54$ & $118.50 \pm 12.02$ & $P=0.2525(N S)$ \\
\hline
\end{tabular}

*Statistical Significance at 5\%: ** Statistical Significance at 1\%: NS Not Significant. 
Table 7 show the trend of mean SBP changes in the two groups. It can be seen that there is no significant difference between the SBPs of the two groups in the first eight minutes. At tenth, fifteen, twenty and twenty fifth minute the fall in systolic blood pressure in Group 1 was greater than that in Group 2 and it was statistically significant.

\begin{tabular}{|c|c|c|c|}
\hline TIME & $\begin{array}{r}\text { GROUP } 1 \\
\text { Mean } \pm \text { S D }\end{array}$ & $\begin{array}{r}\text { GROUP } 2 \\
\text { Mean } \pm \text { S D }\end{array}$ & $P$ value \\
\hline Baseline & $90.2099 \pm 6.7056$ & $90.6065 \pm 6.8423$ & $\mathrm{P}=0.7704$ (NS) \\
\hline After Pre loading & $91.6231 \pm 6.3575$ & $92.9165 \pm 5.6262$ & $P=0.2840$ (NS) \\
\hline $1 \mathrm{~min}$ & $93.2173 \pm 5.7013$ & $94.1187 \pm 5.6596$ & $P=0.4295$ (NS) \\
\hline $2 \min$ & $90.0450 \pm 5.4516$ & $91.0163 \pm 5.6223$ & $\mathrm{P}=0.3826(\mathrm{NS})$ \\
\hline $4 \mathrm{~min}$ & $87.0882 \pm 5.1910$ & $88.1777 \pm 4.8787$ & $P=0.2822(N S)$ \\
\hline $6 \mathrm{~min}$ & $84.7238 \pm 4.8579$ & $85.7416 \pm 4.4343$ & $P=0.2766$ (NS) \\
\hline $8 \mathrm{~min}$ & $82.6642 \pm 4.4239$ & $83.2086 \pm 5.8227$ & $P=0.5998(N S)$ \\
\hline $10 \mathrm{~min}$ & $79.1946 \pm 4.0543$ & $82.1058 \pm 5.0117$ & $\mathrm{P}=0.0001(* *)$ \\
\hline $15 \mathrm{~min}$ & $75.1396 \pm 5.0388$ & $79.3759 \pm 5.4915$ & $\mathrm{P}=0.0001\left(^{* *}\right)$ \\
\hline $20 \mathrm{~min}$ & $76.2224 \pm 5.5825$ & $79.2195 \pm 5.9968$ & $\mathrm{P}=0.0003(* *)$ \\
\hline $25 \mathrm{~min}$ & $78.1459 \pm 4.7659$ & $79.5896 \pm 5.4420$ & $P=0.1614$ (NS) \\
\hline $30 \mathrm{~min}$ & $79.8858 \pm 4.0379$ & $80.5063 \pm 5.5825$ & $P=0.5259$ (NS) \\
\hline $35 \mathrm{~min}$ & $80.2079 \pm 4.0959$ & $81.5797 \pm 5.6534$ & $P=0.1681(N S)$ \\
\hline $40 \mathrm{~min}$ & $81.3493 \pm 3.5067$ & $82.1862 \pm 5.2259$ & $P=0.3497(N S)$ \\
\hline $45 \mathrm{~min}$ & $81.8540 \pm 3.8424$ & $83.0894 \pm 5.8923$ & $P=0.2177(N S)$ \\
\hline $50 \mathrm{~min}$ & $82.0478 \pm 4.3031$ & $83.0363 \pm 5.4530$ & $P=0.3168$ (NS) \\
\hline $55 \mathrm{~min}$ & $82.2986 \pm 4.0262$ & $82.1591 \pm 5.4091$ & $P=0.8840$ (NS) \\
\hline $60 \mathrm{~min}$ & $82.9530 \pm 4.1283$ & $82.8597 \pm 4.7023$ & $P=0.9162(N S)$ \\
\hline $70 \mathrm{~min}$ & $84.4373 \pm 6.4899$ & $81.9200 \pm 7.2452$ & $P=0.0703(N S)$ \\
\hline $80 \mathrm{~min}$ & $84.9374 \pm 5.7113$ & $83.6136 \pm 5.0596$ & $P=0.2228(N S)$ \\
\hline $90 \mathrm{~min}$ & $84.7200 \pm 5.8804$ & $84.7767 \pm 4.2918$ & $P=0.9562$ (NS) \\
\hline $100 \mathrm{~min}$ & $86.3315 \pm 5.1356$ & $85.4975 \pm 5.2888$ & $P=0.4257$ (NS) \\
\hline $110 \min$ & $86.9873 \pm 5.6318$ & $87.1550 \pm 1.6476$ & $P=0.8406$ (NS) \\
\hline $120 \mathrm{~min}$ & $86.4675 \pm 3.9236$ & $87.3400 \pm 20.2657$ & $P=0.1772$ (NS) \\
\hline
\end{tabular}

*Statistical Significance at 5\%: ** Statistical Significance at 1\%: NS Not Significant.

Table 8 show the trend of change in mean arterial pressure in the two groups. It can be seen that there is no significant change in MAP in the two groups in the first eight minutes after SAB. In the 10th, 15th and 20th minute interval after SAB, it can be seen that Group 1 had a significant fall in MAP when compared to Group 2.

Table 9: Ephedrine dose requirements

\begin{tabular}{cccc}
\hline Dose in $\mathrm{mg}$ & Number of patients & Number of patients & P Value \\
\hline No of Dose requirement & GROUP 1 & GROUP 2 & \\
Single Bolus (6mg) & 39 & 46 & \\
>One Bolus & 7 & 3 & \\
Total Dose requirement & 4 & 1 & $\mathrm{P}=0.04995\left(^{*}\right)$ \\
Inference & 11 & 4 &
\end{tabular}

*Statistical Significance at 5\%: ** Statistical Significance at 1\%: NS Not Significant.

Table 9 shows the requirements of ephedrine boluses in treating hypotension. In Group 1, out of 50 patients 11 patients required treatment with ephedrine and 4 out of 11 patients required a repeat bolus. In Group 2, 4 patients required treatment with ephedrine and 1 out of 4 patients required a repeat bolus.

Table 10: Complications

\begin{tabular}{cccc}
\hline Group & Bradycardia & Nausea and vomiting & Allergic reactions \\
\hline Group 1 & 1 & 2 & 0 \\
Group 2 & - & - & - \\
\hline
\end{tabular}

One patient in Group 1 and none in Group 2 had Bradycardia. In Group 1 two patients had Nausea and vomiting and None in Group 2. No patients had Allergic reactions in Group 1 and none in Group 2. 


\section{DISCUSSION}

Hypotension during subarachnoid block is the result of sympathetic blockade leading to relative hypovolemia and decreased venous return. The prophylactic administration of crystalloid before regional anaesthesia has been shown to be ineffective in eliminating spinal anaesthesia-induced hypotension ${ }^{41}$. So, attention has been focused on the prophylactic administration of colloid solutions for the prevention of hypotension during spinal anaesthesia. Theoretically, a colloid solution is the more logical choice in preventing hypotension during subarchnoid block, since it remains in the intravascular compartment for a longer period depending on its physical properties. Various colloid solutions used for this purpose are supposed to have different haemodynamic effects depending upon physicochemical properties of them. The present study however was conducted to compare two colloid solutionsHaemaccel and hydroxyethyl starch $6 \%$ for their use as preloading plasma volume expanders to prevent spinal anaesthesia induced hypotension. In our study we randomized 100 patients into 2 groups with 50 patients each. Group 1 received $10 \mathrm{ml} / \mathrm{kg}$ of Haemaccel and Group 2 received $10 \mathrm{ml} / \mathrm{kg}$ of $6 \%$ hydroxyethyl starch. The incidence of hypotension after 8 minute of SAB was higher in Group 1 as compared to Group 2. Group 1 patients had a incidence of $9 \%$ of hypotension and Group 2 had $4 \% .11$ patients in Group 1 and 4 patients in Group 2 required vasopressor for the management of hypotension. Prerana P. Shroff et al. ${ }^{42}$ in 2007 compared the effects of polygeline and HES as volume preload before spinal anaesthesia. They found that the decline in haemodynamic parameters after spinal anaesthesia was less in HES and the number of patients who developed hypotension and needed ephedrine were more in Group Polygeline. Vercauteren et al. ${ }^{43}$ in 1996 compared HES with modified gelatin as volume preload before spinal anaesthesia for caesarean section. They studied 90 patients undergoing elective caesarean section under spinal anaesthesia who received ringer lactate (LR) $1000 \mathrm{ml}$ with upto $1000 \mathrm{ml}$ of modified gelatin, LR $1000 \mathrm{ml}$ with upto $1000 \mathrm{ml}$ of hydroxyethyl starch $6 \%$ (HES) or only upto $1000 \mathrm{ml}$ of $6 \%$ HES. Lumbar puncture was performed as soon as $500 \mathrm{ml}$ of the colloid was infused. The incidence of hypotension, number of patients requiring a vasopressor and doses of ephedrine required to restore arterial pressure were significantly lower in favour of those receiving the crystalloid - HES combination. A study by Sharma et al. ${ }^{44}$ has shown that intravenous infusion of $500 \mathrm{ml}$ of $6 \%$ hetastarch is more effective than $1000 \mathrm{ml}$ of lactated Ringer's solution in attenuating spinal anaesthesia induced hypotension in women undergoing postpartum tubal ligation. Incidence of hypotension was $52 \%$ in the lactated Ringer's solution and $16 \%$ in the hetastarch group. Karinen et al. ${ }^{45}$ in 1995 aimed to compare the effect of Ringer's lactate and Hydroxyethyl starch preloading on the haemodynamic state during spinal anaesthesia on patients undergoing caesarean section. The study showed high incidence of maternal hypotension in the crystalloid (62\%) group as compared to the colloid group (38\%). Baraka et al..$^{13}$ in 1994 compared intravascular administration of polymerized gelatin and isotonic saline before spinal anaesthesia for prevention of spinal anaesthesia induced hypotension. They reported a $11 \%$ incidence of hypotension after administration of 7 $\mathrm{ml} / \mathrm{kg}$ of $3 \%$ gelatin compared with $52 \%$ after same volume of crystalloid in males undergoing transurethral resection of prostate under spinal anaesthesia. Shapira et $a l^{46}$ in 1991 aimed to determine different aspects concerning hypotension and its prevention following spinal anaesthesia by preloading the patients with Haemaccel and ringer's lactate respectively. They found that the systolic blood pressure decrease was significantly greater in the crystalloid group. The average decrease in systolic blood pressure in the Haemaccel group was $6 \mathrm{~mm}$ $\mathrm{Hg}$ and in the ringer group it was $16 \mathrm{mmHg}$. Mortelmans et al. $(1995)^{47}$ conducted a study to determine the effects on intravascular volume and coagulation of $2000 \mathrm{ml}$ of the two-isooncotic artificial colloids: $6 \%$ hydroxy ethyl starch (HES) and 3\% modified gelatin (GEL). Forty two patients, scheduled for primary total hip replacement were allocated randomly to receive HES or GEL during acute normovolemic haemodilution. This study quantifies a poorer volume effect of GEL and a higher blood loss with hydroxyethyl starch. Riley et al. (1995) ${ }^{12}$ conducted a study among forty non labouring ASA grade I and II women having non urgent caesarean section to determine whether preoperative administration of $6 \%$ hydroxyethyl starch decreases the incidence and severity of hypotension after spinal anaesthesia for elective caesarean section. The study concluded that $6 \%$ of HES plus ringer lactate is more effective than ringer lactate alone. Hydroxyethyl starch $6 \%$ $(130 / 0.4)$ is a synthetic colloid solution with a mean molecular weight of $2,00,000$. The $\mathrm{pH}$ of this hydroxyethyl starch solution is $4-5.5$, the osmolarity is $308 \mathrm{mOsm} / \mathrm{L}$, and the colloid oncotic pressure $(36 \mathrm{~mm} \mathrm{Hg})$ is similar to that of serum. Its intravascular half-life is 1.4 hours and it has the capacity to expand plasma volume to a volume that is greater than the volume infused. Advantages of hydroxyethyl starch include a lower incidence of anaphylactic reactions as compared to other colloids and this has been depicted in the present study too. Haemaccel is isooncotic, has a mean half-life of 4-5 hours. It causes Allergic reaction, probably due to histamine release. In our study 2 patients had minor allergic reactions in the form of urticarial rash which subsided spontaneously. The present study confirms that HES is better colloid than Haemaccel 
in preventing hypotension in patients undergoing surgeries under SAB.

\section{CONCLUSION}

In conclusion we found that preloading with colloids reduces the incidence spinal anaesthesia induced hypotension and 6\% HES is safer and effective than Haemaccel in preventing hypotension and achieving haemodynamic goals in patients undergoing surgeries under SAB. Thus among colloids, HES $6 \%$ appears to be a promising plasma volume expander.

\section{REFERENCES}

1. Carpenter RL, Caplan RA, Brown DL, Stephenson C, Wu $\mathrm{R}$. Incidence and risk factors for side effects of spinal anaesthesia. Anesthesiology 1992; 76: 906-16.

2. Covino BG, Scott DB, Lambert DH. Handbook of spinal anaesthesia and analgesia. Philadelphia: WB Saunders, 1994.

3. Murray AM, Morgan M, Whitwam JG. Crystalloid versus colloid for circulatory preload for epidural caesarean section. Anaesthesia 1989; 44: 463-6.

4. Rout CC, Rocke DS, Levin J, Gouws E, Reddy DA. A reevaluation of the role of crystalloid administration for the prevention of hypotension associated with spinal anaesthesia for elective cesarean section. Anesthesiology 1993; 79: 262-9.

5. Rout CC, Akoojee SS, Rocke DA, Gouws E. Rapid administration of crystalloid preload does not decrease the incidence of hypotension after spinal anaesthesia for elective cesarean section. British Journal of Anaesthesia 1992; 68: 394-7.

6. Rocke DA, Rout CC. Volume preloading, spinal hypotension and Cesarean section. British Journal of Anaesthesia 1995; 75: 257-9.

7. Venn PJ, Simpson DA, Rubin AP, Edstrom HH. Effect of fluid preloading on cardiovascular variables after spinal anaesthesia with glucose-free $0.75 \%$ bupivacaine. British Journal of Anaesthesia 1989; 63: 682-7.

8. Coe AJ, Revanas B. Is crystalloid preloading useful in spinal anaesthesia in the elderly? Anaesthesia 1990; 45: 241-3.

9. Buggy D, Higgins P, Moran C, O'Brien D, O'Donovan F, McCarroll M. Prevention of spinal anaesthesia-induced hypotension in the elderly: comparison between preanaesthetic administration of crystalloids, colloids, and no prehydration. Anesth Analg 1997; 84: 106-10.

10. Casati A, Fanelli G, Berti M, Boccaria P, Agostini M. Cardiac performance during unilateral lumbar spinal block after crystalloid preload. Can J Anaesth 1997; 44: 623-8.

11. Arndt JO, Bomer W, Krauth J, Marquardt B. Incidence and time course of cardiovascular side effects during spinal anaesthesia after prophylactic administration of intravenous fluids or vasoconstrictors. Anesth Analg 1998; 87: 347-54.

12. Riley ET, Cohen SE, Rubenstein AJ, Flanagan B. Prevention of hypotension after spinal anaesthesia for Cesarean section: Six percent hetastarch versus lactated Ringer's solution. Anesth Analg 1995; 81: 838-842.
13. Baraka AS, Taha SK, Ghabach MB, Sibaii AA, Nader AM. Intravascular administration of polymerized gelatin versus isotonic saline for prevention of spinal induced hypotension. Anesth Analg 1994; 78: 301-305.

14. Critchley LAH. Hypotension, subarachnoid block and the elderly patient. Anaesthesia 1996; 51: 1139-1143.

15. Critchley LAH, Stuard JC, Short TG, Gin T. Haemodynamic effects of subarachnoid block in elderly patients. British Journal of Anaesthesia 1994; 73: 464-470.

16. Longnecker DE, Tinker JH, Morgan GE. Spinal anaesthesia in Principles and practise Of anaesthesiology volume2, 1998.

17. Donald S. Prough, Mali Matheu. Acid- Base, fluids and electrolytes. In: Paul G. Barash, Bruce F. Cullen, Robert K. Stoelting ed. Clinical Anaesthesia. Fourth edition. Lippincott Williams and Wilkins, 2001: 175-177.

18. Alan D. Kaye and Alan W. Grogono. Fluid and Electrolyte physiology. In: Ronald D Miller. Ed. Anaesthesia. Fifth edition. Volume I. Philadelphia: Churchill Livingstone, 2000: 1602-1604.

19. Sommermeyer K, Cech F, Schmidt M, Weidler B. Hydroxyethyl starch in clinical use: A physical-chemical characterization. German original published in Krankenhaus pharmacie: 1987; 8: 271.

20. Yacobu A, Stoll RG, Sum CY. Pharmacokinetics of hydroxyethyl starch in normal subjects. J Clin Pharmacol 1982; 22: 206-12.

21. Kaye AD, Kucera IJ. Intravascular fluid and electrolyte physiology. In, Miller RD, ed. Miller's Anesthesia, $6^{\text {th }}$ edition. Philadelphia, Churchill Livingstone: 2005, 176398.

22. Martino P, ed. Colloid and crystalloid resuscitation. The ICU Book, $3^{\text {rd }}$ edition. Philadelphia, Churchill Livingstone: 2007, 233-54.

23. Dubois MJ, Vincent JL. Colloid Fluids. In, Hahn RG, Prough DS, Svensen CH, eds. Perioperative Fluid Therapy, $1^{\text {st }}$ edition. New York, Wiley: 2007, 153-611.

24. Solanke TF, Khwaja MS, Kadomemu EL. Plasma volume studies with four different plasma volume expanders. J Surg Res 1971; 11: 140-43.

25. Linder P, Ickx B. The effects of colloid solutions on hemostasis. Can J Anesth 2006; 53: s30-39.

26. Barron ME, Wilkes, Navickis RJ. A systematic review of the comparative safety of colloids. Arch Surg 2004; 139: 552-563.

27. Treib J, Haass A, Pindur G. Coagulation disorders caused by hydroxyethyl starch. Thromb Haemost 1997; 78: 97483.

28. Sirti C, Laubenthal H, Zumtobel V, Kraft D, Jurecka W. Tissue deposits of hydroxyethyl starch (HES): dosedependent and time- related. Br J Anaesth 1999; 82: 510513.

29. Schortgen F et al.. Effects of hydroxyethylstarch and gelatin on renal function in severe sepsis: a multicentre randomized study. Lancet 2001; 357: 911-16.

30. Davidson IJ. Renal impact of fluid management with colloids: a comparative review. Eur J Anaesth 2006; 23: 721-738.

31. Cittanova ML, Leblanc I, Legendre $\mathrm{CH}$, et al.. Effect of hydroxyethylstarch in brain-dead kidney donors on renal function in kidney-transplant recipients. Lancet 1996: 348; 1620-1622. 
32. Roberts J, Nightingale P. Properties and use of gelatins. In, Webb AR, ed. Therapeutics. Germany, Braun: 2003,4552.

33. Goodnough L, Monk T. Autologous transfusion: in Miller's Anesthesia. ed Miller RD, $6^{\text {th }}$ edition. Philadelphia, 2005: 1831-1843.

34. Nyhan D, Johns RA. Anesthesia for cardiac surgery procedures: in Miller's Anesthesia, ed Miller RD, $6^{\text {th }}$ edition, Philadelphia, 2005, 1941-2004.

35. Tabuchi N, Haan J, Gallandat RC, Boonstra PW, vanOeveren W. Gelatin use impairs platelet adhesion during cardiac surgery. Thromb Haemost 1995; 74: 144751.

36. Gines A, Fernandez-Esparrach G, Monescillo A, et al. Randomized trial comparing albumin, dextran-70 and polygeline in cirrhotic patients with ascitis treated by paracentesis. Gasteroenterology 1996; 111: 1002-10.

37. Bernard Rosner (2000). Fundamentals of Biostatistics, $5^{\text {th }}$ Edition; Duxbury: 80-240.

38. John Eng (2003). Sample size estimation. How many Individuals Should be Studied? Radiology; 227: 309-313.

39. Sunder Rao $\mathrm{P}$ S, Richard J. An Introduction to Biostatistics, A manual for students in health sciences. New Delhi; Prentice hall of India: 86-160.

40. M. Venkataswamy Reddy (2002). Statistics for Mental Health Care Research, NIMHANS publication; INDIA: 108-144.

41. Mortelmans, Gerry, Verbruggen, Arnout, Jef. Effects of $6 \%$ HES and $3 \%$ modified gelatin on intravascular volume and coagulation during intraoperative haemodilution. Anesth Analg 1995; 81: 1235-42.

42. Prerana P, Sadanand Kulkarni, Smita Lela, Surekha Kamath, Latha Chaudhari, Dewoolkar LV. Randomized, comparative study between polygeline and hydroxyethyl starch (130/0.4) as volume preload before spinal anaesthesia. J Anaesth Clin Pharmacology 2007; 23(30): 269-272.

43. Vercauteren MP, Hoffmann V, Coppejans HC, Van Steenberge AC, Adriansen HA. HES compared with modified gelatin as volume preload before spinal anaesthesia for caesarean section. British Journal of Anaesthesia 1996; 76: 731-733.

44. Sharma SK, Gajraj NM, Sidwai JE. Comparison of hypotension during spinal anaesthesia: A comparison of Hetastarch versus lactated Ringer`s solution. Anesth Analg 1997; 84: 111-114.

45. Karinen J, Rasanen J, Alahuhta S, Jouppila R, Jouppila P. The effect of crystalloid and colloid preloading on uteroplacental and haemodynamic state during spinal anaesthesia for caesarean section. British Journal of Anaesthesia 1995; 75: 531-535.

46. Shapira S.C et al.. A comparison of intravenous loading for epidural with ringer lactate and polygeline. European Journal of Pain 1991; 12:100-103.

47. Mortelmans, Gerry, Verbruggen, Arnout, Jef. Effects of $6 \%$ HES and $3 \%$ modified gelatin on intravascular volume and coagulation during intraoperative haemodilution. Anesth Analg 1995; 81: 1235-42.

\section{Source of Support: None Declared Conflict of Interest: None Declared}

Policy for Articles with Open Access:

Authors who publish with MedPulse International Journal of Anesthesiology (Print ISSN:2579-0900) (Online ISSN: 2636-4654) agree to the following terms: Authors retain copyright and grant the journal right of first publication with the work simultaneously licensed under a Creative Commons Attribution License that allows others to share the work with an acknowledgement of the work's authorship and initial publication in this journal.

Authors are permitted and encouraged to post links to their work online (e.g., in institutional repositories or on their website) prior to and during the submission process, as it can lead to productive exchanges, as well as earlier and greater citation of published work. 